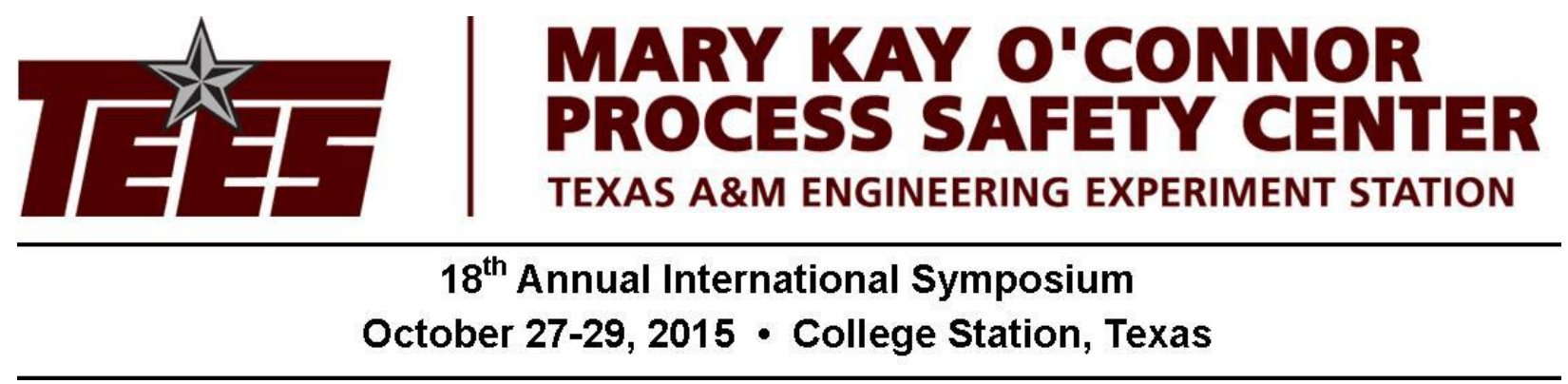

\title{
Pressure Relief Sizing of Reactive System using DIERS Simplified Methods and Dynamic Simulation Method
}

\author{
Surendra K. Singh*, Richard Huh \\ ioKinetic, LLC. \\ 95 Stiles Road, Salem, New Hampshire 03079, USA \\ *Presenter Email: Singh@ioKinetic.com
}

\begin{abstract}
Incidents involving uncontrolled chemical reactions continue to result in fatality, injury and economic loss. These incidents are often the result of inadequate pressure relief system designs due to a limited knowledge of the chemical reactivity hazard. A safe process design requires knowledge of the chemical reactivity of desired as well as undesired chemical reactions due to upset conditions. Simplified, cost effective methods to relief system sizing are presented by The Design Institute of Emergency Relief Systems (DIERS). They require multiple experiments and sizing is only valid for the system composition and thermal inertia represented by the small scale experiments. Results are often conservative, especially for gassy systems. Detailed, dynamic computer simulation is highly accurate and can be used for iterative design and multiple scenario evaluation.

In this study, an accelerating rate calorimeter (ARC®) and a low thermal inertia calorimeter (automatic pressure tracking adiabatic calorimeter - APTAC ${ }^{\mathrm{TM}}$ ) were used to collect chemical reactivity data for the dicumyl peroxide and toluene system. Results of the pressure relief system sizing using the two methodologies are presented and compared.

\section{Introduction}

The detailed methods described in the DIERS Project Manual ${ }^{1}$ and by Melhem ${ }^{2}$, advocate a fundamental approach to pressure relief design, especially for a reactive system. In this approach, the reaction chemistry is qualified using small-scale experiments. A kinetic model of the system is developed, including an estimation of the vapor-liquid equilibrium of the reactants and products. Simulations are completed of the full scale system coupling fluid dynamics to design the pressure relief system. The method is highly accurate, can handle complex systems, and is valuable for sensitivity analysis (i.e., iterative design and what-if analysis). The direct evaluation of the impact of temperature, pressure, composition, fill level, solvent boiling point, reduced
\end{abstract}


charge, etc. can be simply and quickly completed. The detailed method also provides the necessary flow data for relief containment design (if required), structural support, etc. It requires expert skill for establishing kinetic information from the rate of chemical energy release and thermophysical properties of the system.

The simplified analytical and direct scale-up methods explained in the DIERS manual ${ }^{1}$, while mostly applicable to non-reactive systems, are often applied to reactive systems because of their simplicity. The analytical methods described in Appendix VI-A of the DIERS Project Manual include FAI's (Fauske \& Associates, LLC.) nomograph/analytical method and Leung's analytical methods ${ }^{3}$. The DIERS Project Manual also presents a direct scale-up method based on relief area to vessel charge scaling.

The scale-up data, developed from analytical and direct-scale-up methods, is only valid for the system composition and thermal inertia represented by the small-scale experiments; the results are often conservative (especially for gassy systems), and the presence of long inlet lines and the impact of downstream equipment are not considered. Sensitivity analysis requires additional experiments. There are many runaway reaction emergency relief system design computer programs including DIERS SAFIRE and the SuperChems ${ }^{\mathrm{TM}}$ component of ioMosaic Corporation's Process Safety Office ${ }^{\mathrm{TM}}$ software.

Use of adiabatic runaway reaction test information in combination with computer simulation is a powerful method to design a pressure relief system when consideration of alternatives is required. It allows quantification of rates of heat release and pressure and temperature changes for a variety of operating and upset conditions.

Once a chemical reaction model is developed, various design possibilities can be examined, for example operating temperature, feed rate, cooling capacity under upset conditions, heat loss, fire exposure heat flux and fire exposure duration. A pressure relief system could be evaluated for relief device set pressure, vessel fill ratio, volatile solvents, relief valve vs rupture disc, vent piping etc.

The detailed scale-up method is a three step approach:

- Conduct a closed small-scale adiabatic test using accelerating rate calorimeter $\left(\mathrm{ARC}^{\circledR}\right)$ and/or automatic pressure tracking adiabatic calorimeter $\left(\mathrm{APTAC}^{\mathrm{TM}}\right)$.

- Define reaction stoichiometry using measured vapor-liquid equilibrium and define reaction model in order to develop a model that simulates the adiabatic test

- Simulate the actual full-scale vessel

\subsection{Adiabatic Calorimetry Test}

The accelerating rate calorimeter $\left(\mathrm{ARC}^{\circledR}\right)$ and automatic pressure tracking adiabatic calorimeter $\left(\mathrm{APTAC}^{\mathrm{TM}}\right.$ ) generate data on the temperature and pressure response of the system to heating. This data forms the basis for development of the kinetic model and estimation of the vapor-liquid equilibrium.

The data sets from ARC/APTAC experiments provide a good understanding of the nature of the reactions involved. Key parameters obtained from the experiments include temperature and 
pressure profiles, reaction onset temperatures, heats of reaction, reaction kinetic parameters, and temperature and pressure rise rates of the exothermic reactions.

\subsection{Reaction Kinetics Model Development}

A kinetic model is developed from the closed ARC/APTAC test data to find a good fit based on the measured data. The slope of temperature rise rate vs 1/T (ARC data set) is the activation energy and its intercept is the pre-exponential factor. The heat of reaction is calculated from adiabatic temperature rise and heat capacity of the mixture. By selecting the thermodynamic properties of reactants and products in stoichiometric concentration, order of reaction and applying kinetic parameters, a kinetic model is developed. The kinetic model fits the ARC experimental temperature, pressure, and time history. SuperChems database has thermodynamic properties of $>4500$ chemicals.

\subsection{Pressure Relief System Design}

To complete the pressure relief system evaluation, simulations of the full-scale system are completed, using the kinetic model. This model is applied to a full-scale system to simulate the system response under thermal runaway scenarios. Various pressure relief system designs can be evaluated until an adequate system is found.

\subsection{Application to a 400 gallon Reactor System}

The reactor is 400 -gallons with a rated MAWP of $58 \mathrm{psig}$ at $400^{\circ} \mathrm{C}$. It is equipped with one top mounted rupture disc which is vented directly to atmosphere. As part of the operating procedure, $400 \mathrm{~kg}$ of $50 \%$ dicumyl peroxide is stored into the vessel at room temperature. The kinetic model developed from the ARC experimental data set is used for simulating this system.

Murphy ${ }^{4}$ conducted adiabatic calorimetry study of dicumyl peroxide in toluene system. Melhem ${ }^{2}$ developed reaction kinetic model and relief size predictions of this system. Singh et $\mathrm{al}^{5}$ used calorimeter data generated by low thermal inertia calorimeter called automatic pressure tracking adiabatic calorimeter (APTAC) to estimate required relief area using DIERS analytical and direct scale-up methods. In this method, sizing is estimated for both vapor and two phase flow (hybrid) systems.

In this study, required relief areas are estimated using dynamic computer simulation program and reaction kinetic model developed from an accelerating rate calorimeter (ARC@) test. The relief area was estimated for flow regimes of vapor and two phase flow regime (homogenous and bubbly). These results are compared with the required relief area estimates using DIERS analytical and direct scale-up methods, earlier reported by Singh et $\mathrm{al}^{5}$. Vent sizing results from the two methodologies are presented and compared. 


\section{Experimental}

\subsection{ARC test design}

The accelerating rate calorimeter $\left(\mathrm{ARC}^{\circledR}\right)$ generates data that can be used to size pressure relief systems by dynamic simulation method. It is based on the technology developed and promoted by DIERS. The key characteristics of the ARC test are listed below and described in the Operation Manual ARC $254^{6}$.

One closed adiabatic ARC test was conducted with a recipe amount of 50\% dicumyl peroxide in toluene in nitrogen. The tests were run in heat-wait-search mode from $50^{\circ} \mathrm{C}$ to $350^{\circ} \mathrm{C}$. The temperature and pressure responses were recorded, as well as the cool down temperature and pressure data once the sample reached $40^{\circ} \mathrm{C}$. The end weight of the test cell and residue were also recorded.

\section{Table 1: Closed ARC Test Information}

\begin{tabular}{|l|c|}
\hline Test Parameters & Closed ARC test $)$ \\
\hline $50 \%$ dicumyl peroxide in toluene mass $(\mathrm{g})$ & 2.0 \\
\hline ARC Test Cell material & $\mathrm{SS}$ \\
\hline Weight of test cell $(\mathrm{g})$ & 17.107 \\
\hline Thermal inertia & 3.28 \\
\hline Vessel volume $(\mathrm{ml})$ & 10.3 \\
\hline Start temperature $\left({ }^{\circ} \mathrm{C}\right)$ & 50 \\
\hline Exotherm sensitivity $\left({ }^{\circ} \mathrm{C} / \mathrm{min}\right)$ & 0.03 \\
\hline
\end{tabular}

\subsection{APTAC test design}

A total of 2 APTAC tests were conducted, one closed test and one vented test. The closed APTAC test was used to estimate relief size considering the vent flow regime as vapor phase. The vented APTAC test was used to estimate the relief size considering the vent flow regime as two phase (hybrid). This test was vented at 58 psig to a vessel open to atmospheric pressure. The test method was developed according to DIERS methodology and the detailed experimental design and calculations are reported in paper of Singh, et al ${ }^{5}$. 


\section{Results and Discussion}

\subsection{Closed ARC Test Results}

Closed ARC test revealed an exotherm with an onset temperature of $95.5^{\circ} \mathrm{C}$ (Figure 1), adiabatic temperature rise of $301{ }^{\circ} \mathrm{C}$ and heat of reaction of $1024 \mathrm{~J} / \mathrm{g}$-dicumyl peroxide. The reaction generated a significant amount of non-condensable gas (150.2 psia). The maximum pressure rise rate was $17.2 \mathrm{psi} / \mathrm{min}$ at $169.8^{\circ} \mathrm{C}$ (Figure 2). The detailed test results are summarized in Table 2 .

Figure 1: Temperature rise rate vs. temperature plots of $50 \%$ dicumyl peroxide in toluene

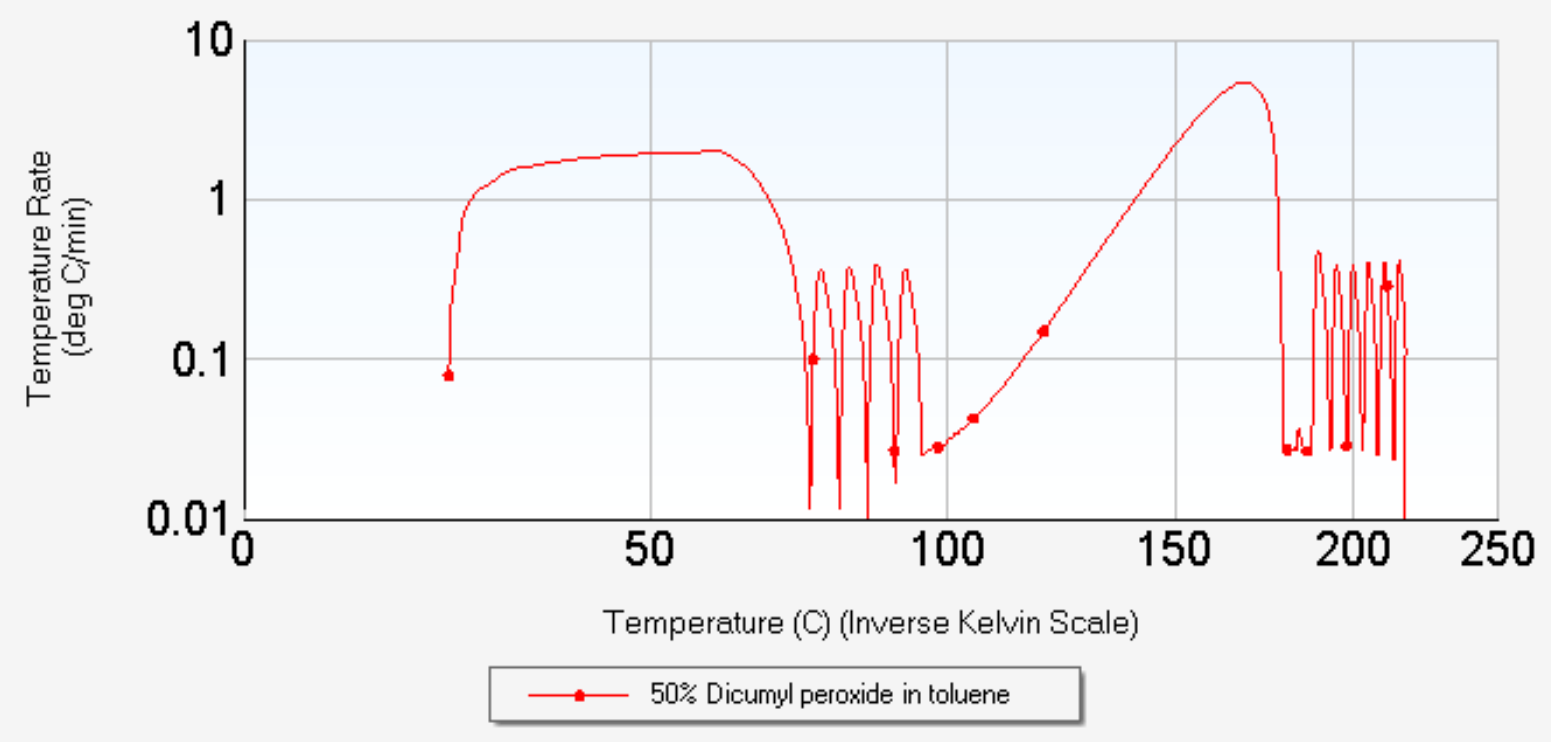


Figure 2: Pressure rise rate vs. temperature plots of $50 \%$ dicumyl peroxide in toluene

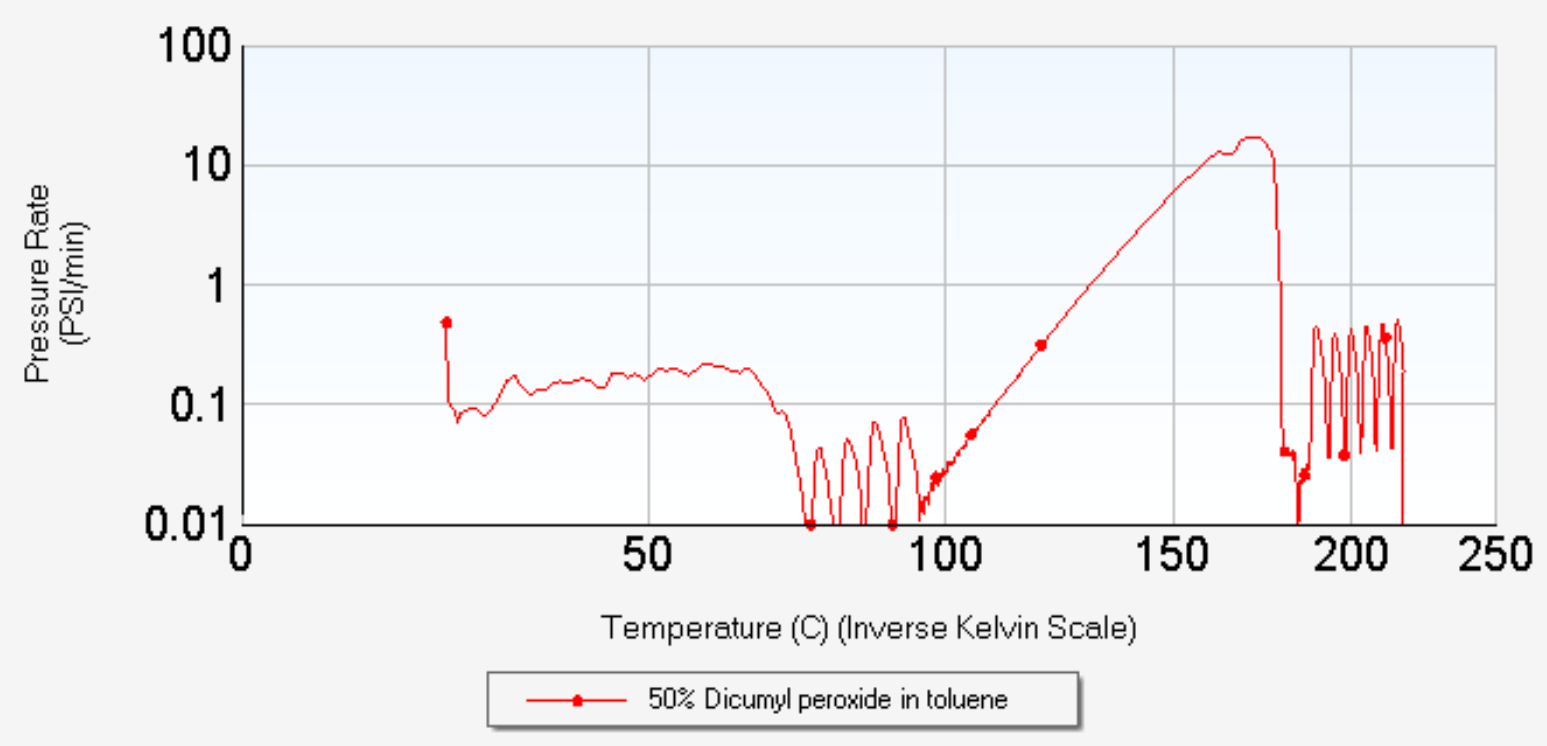

Table 2: Summary of Closed ARC Test results

\begin{tabular}{|l|c|}
\hline Test Parameters & Closed ARC test \\
\hline $50 \%$ dicumyl peroxide in toluene mass $(\mathrm{g})$ & 2 \\
\hline System $\Phi$ factor & 3.28 \\
\hline Onset $\left({ }^{\circ} \mathrm{C}\right)$ & 95.5 \\
\hline Exotherm detection threshold $\left({ }^{\circ} \mathrm{C} / \mathrm{min}\right)$ & 0.03 \\
\hline $\mathrm{dT} / \mathrm{dt}_{\max }\left({ }^{\circ} \mathrm{C} / \mathrm{min}\right)$ & 4.3 \\
\hline $\mathrm{dP}_{\mathrm{di}}$ max $(\mathrm{psi} / \mathrm{min})$ & 17.2 \\
\hline Temperature at $\mathrm{dP} / \mathrm{dt}_{\max }\left({ }^{\circ} \mathrm{C}\right)$ & 169.8 \\
\hline$\Delta \mathrm{T}\left({ }^{\circ} \mathrm{C}\right)$ & 92 \\
\hline$\Delta \mathrm{T}_{\text {ad }}\left({ }^{\circ} \mathrm{C}\right)$ & 301 \\
\hline$\Delta \mathrm{H}_{\mathrm{r}}(\mathrm{J} / \mathrm{g}$ dicumyl peroxide) & 1024 \\
\hline Activation energy $(\mathrm{cal} / \mathrm{gmol})$ & 34,773 \\
\hline Pre-exponential factor $\left(\mathrm{s}^{-1}\right)$ & $1.0 \mathrm{E}+015$ \\
\hline Total weight loss $(\%)$ & 8.2 \\
\hline
\end{tabular}

\subsection{Reaction Kinetics Model Development}

The closed ARC test data was used to develop a reaction kinetic model by Melhem ${ }^{2}$. Test results show a clear single exothermic reaction where dicumyl peroxide decomposes on heating to produce free radicals, which react to form acetophenone $\left(\mathrm{C}_{8} \mathrm{H}_{8} \mathrm{O}\right)$, dimethyl phenyl carbinol $\left(\mathrm{C}_{9} \mathrm{H}_{12} \mathrm{O}\right)$, methane $\left(\mathrm{CH}_{4}\right)$ and toluene $\left(\mathrm{C}_{7} \mathrm{H}_{8}\right)$ as the major products. A stoichiometric balance equation follows:

$\mathrm{C}_{18} \mathrm{H}_{22} \mathrm{O}_{2} \rightarrow 1.613 \mathrm{C}_{8} \mathrm{H}_{8} \mathrm{O}+0.4 \mathrm{C}_{9} \mathrm{H}_{12} \mathrm{O}+0.7 \mathrm{CH}_{4}+0.117 \mathrm{C}_{7} \mathrm{H}_{8}$ 
The decomposition of dicumyl peroxide was considered to be a first order reaction and the heat of reaction was $1,130 \mathrm{~J} / \mathrm{g}$-dicumyl peroxide. Details of the kinetic model fit (blue line) to match the measured data (green line) are shown below in Figures 3 to 5 . The simple first order Arrhenius equation derived is as follow:

$\mathrm{k}=1 \mathrm{E}+015 \exp [-17,500 / \mathrm{T}]$

Figure 3: Pressure vs. temperature plots of $50 \%$ dicumyl peroxide in toluene

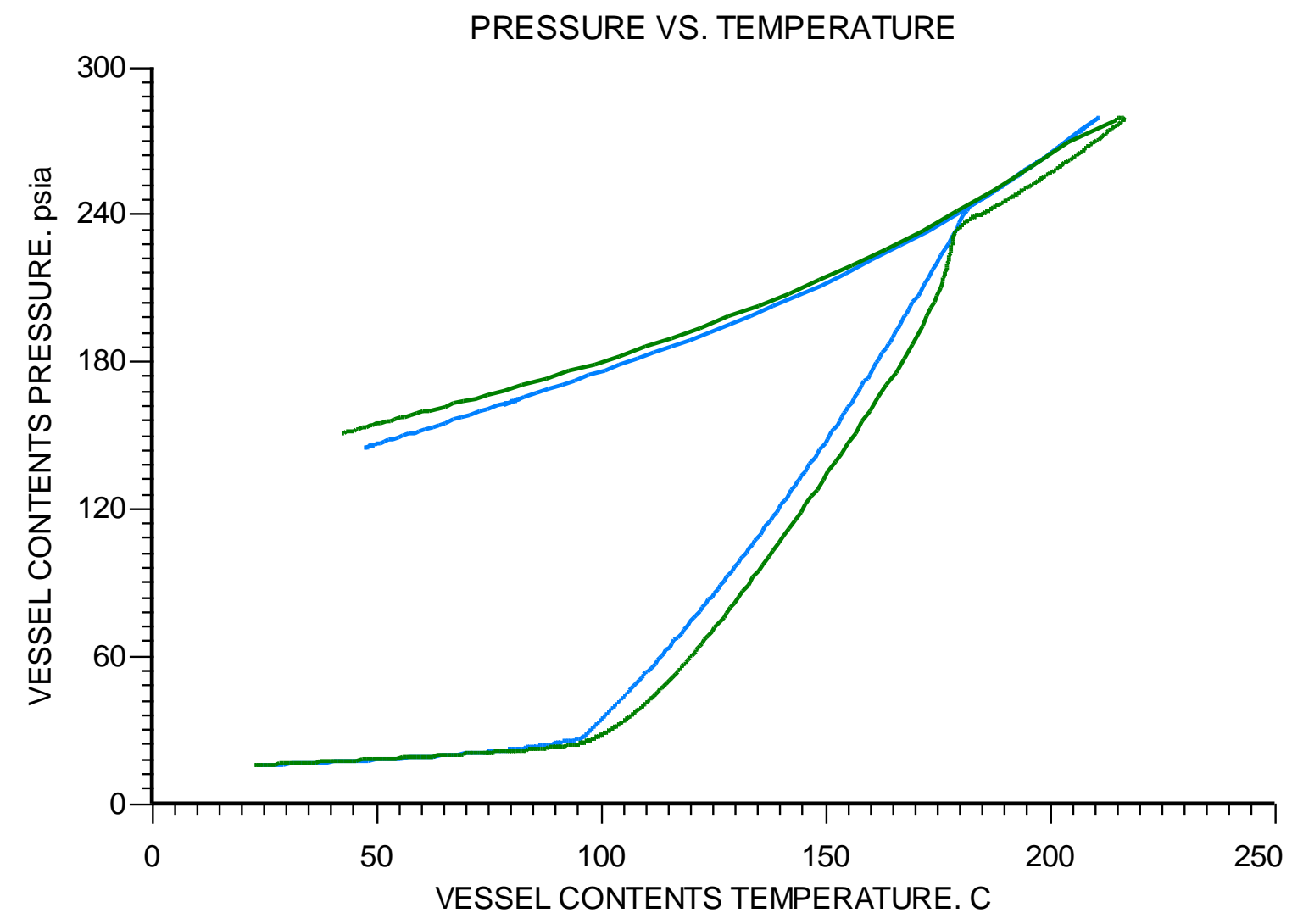


Figure 4: Temperature rise rate vs. temperature plots of $50 \%$ dicumyl peroxide in toluene

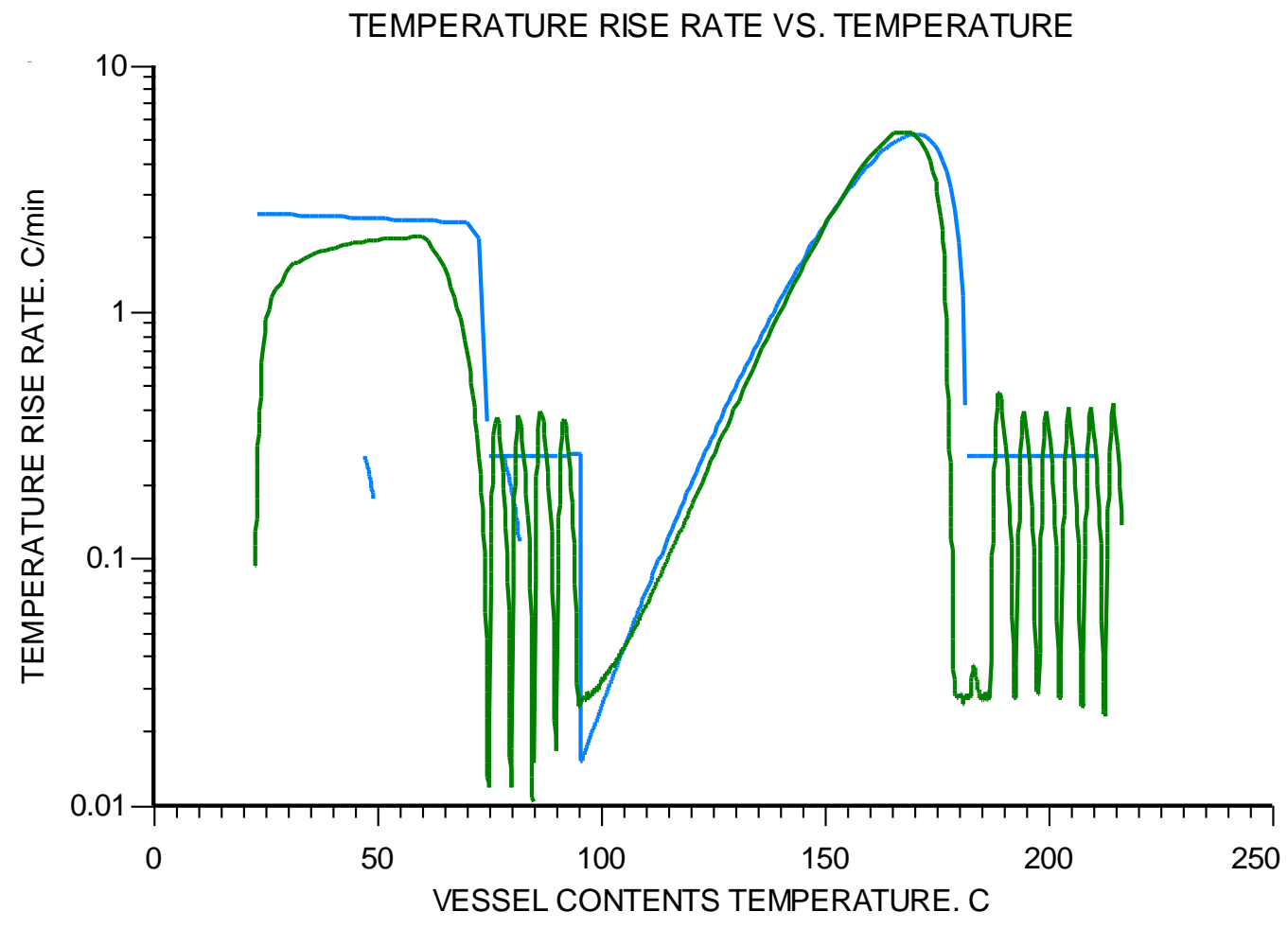


Figure 5: Pressure rise rate vs. temperature plots of $50 \%$ dicumyl peroxide in toluene

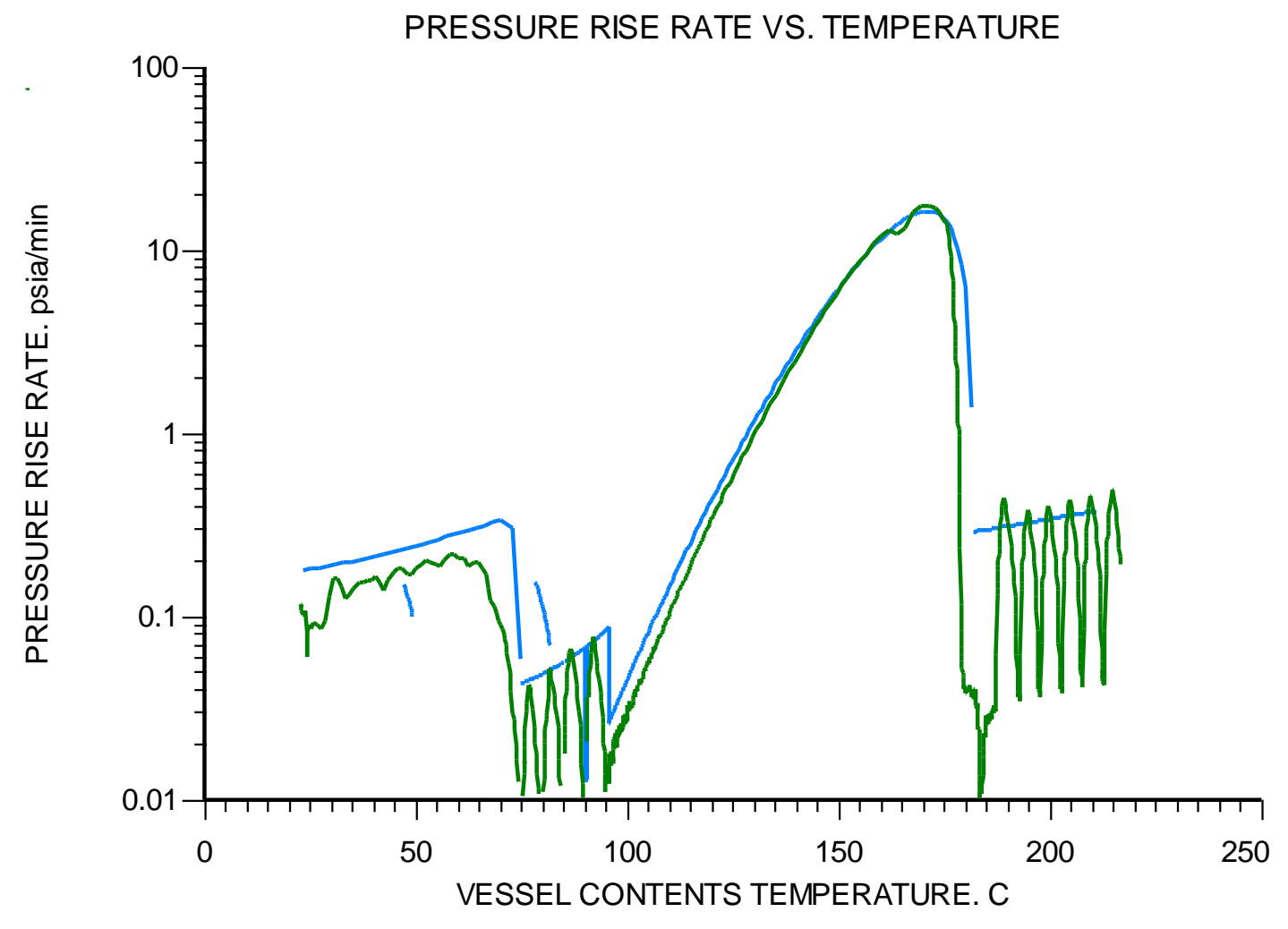

\subsection{Example Pressure Relief System Design}

The intent of this study was to determine the required relief systems for a 400 gallon reactor that contains reactive chemicals using dynamic simulation and compare with DIERS analytical and direct scale-up methods. The data sets for 50\% dicumyl peroxide systems obtained from accelerating rate calorimetry (ARC) experiments provided the basis for the kinetic models used to simulate the reaction system and evaluate the relief requirements due to a process-induced (loss of cooling) runaway reaction.

\subsubsection{Application to Full Scale Vessel or Design Basis}

A 400 gallon vessel containing $400 \mathrm{~kg}$ of 50\% Dicumyl peroxide in a toluene solution has a MAWP of 58 psig and is equipped with a top mounted rupture disc. The vessel has an inside diameter of $3 \mathrm{ft}$, straight side length of $6.564 \mathrm{ft}$, and elliptical 2:1 top and bottom heads. The rupture disc opens directly to ambient pressure at a set pressure $\left(\mathrm{P}_{\text {set }}\right)$ of $58 \mathrm{psig}$. The rupture disc discharge coefficient of 0.5 was considered. The kinetic model developed from the ARC data set for 50\% dicumyl peroxide system was used for simulating this system.

\subsubsection{Rupture disc size estimation using dynamic simulation}


Required relief sizes were evaluated for a runaway reaction scenario using the detailed dynamic simulation method. Calculations were completed for both 2-phase homogeneous flow and bubbly flow. Rupture disc size was estimated in order to keep the vessel pressure from exceeding the maximum allowable accumulated pressure (MAAP) for the considered overpressure scenarios. The relief size estimations are summarized in Table 3 .

\subsubsection{Vapor Flow Regime}

The vessel under a thermal runaway condition resulted in an increase in pressure until the rupture disc burst open at $58 \mathrm{psig}\left(140^{\circ} \mathrm{C}\right)$. Once the rupture disc burst open, the pressure in the vessel dropped immediately to ambient pressure and the temperature dropped to $131.8^{\circ} \mathrm{C}$ (Figures 6 and 7). For the next $0.35 \mathrm{hr}$, the temperature in the vessel kept rising slowly while the pressure remained at ambient pressure. Over this time, the vessel content mass vs. time plot shows that the mass of toluene is decreasing rapidly compared to dicumyl peroxide (Figure 8). When the toluene is nearly gone and approximately $28 \mathrm{lbs}$ of dicumyl peroxide remain in the vessel, the pressure and temperature in the vessel rose sharply until all of the remaining dicumyl peroxide reacted. The rupture disc size required to keep the vessel pressure below the MAAP (63.8 psig) was found to be $405 \mathrm{in}^{2}$.

Figure 6: Vessel pressure vs. time profile of vapor phase relief

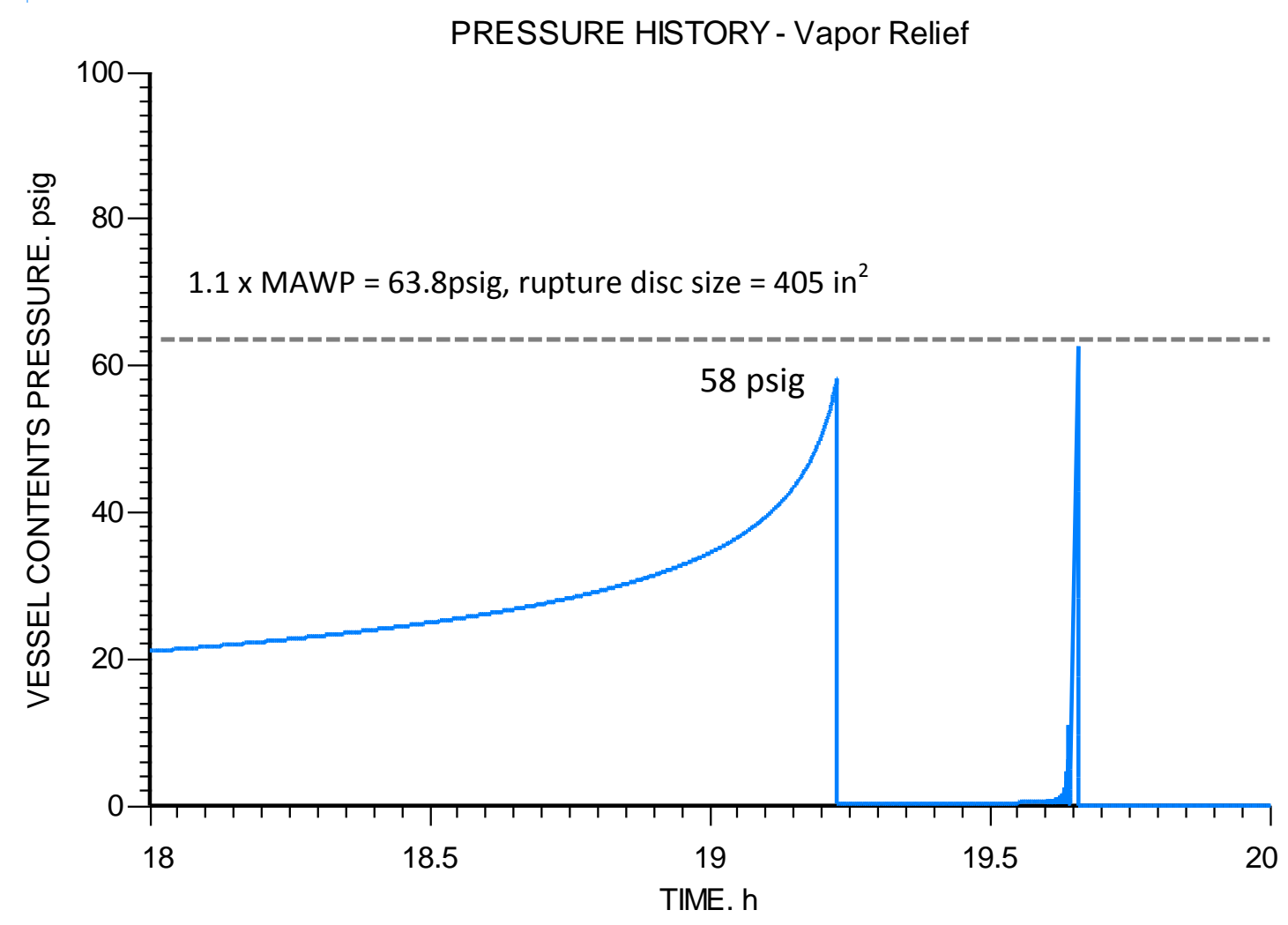

Figure 7: Vessel temperature vs. time profile of vapor phase relief 


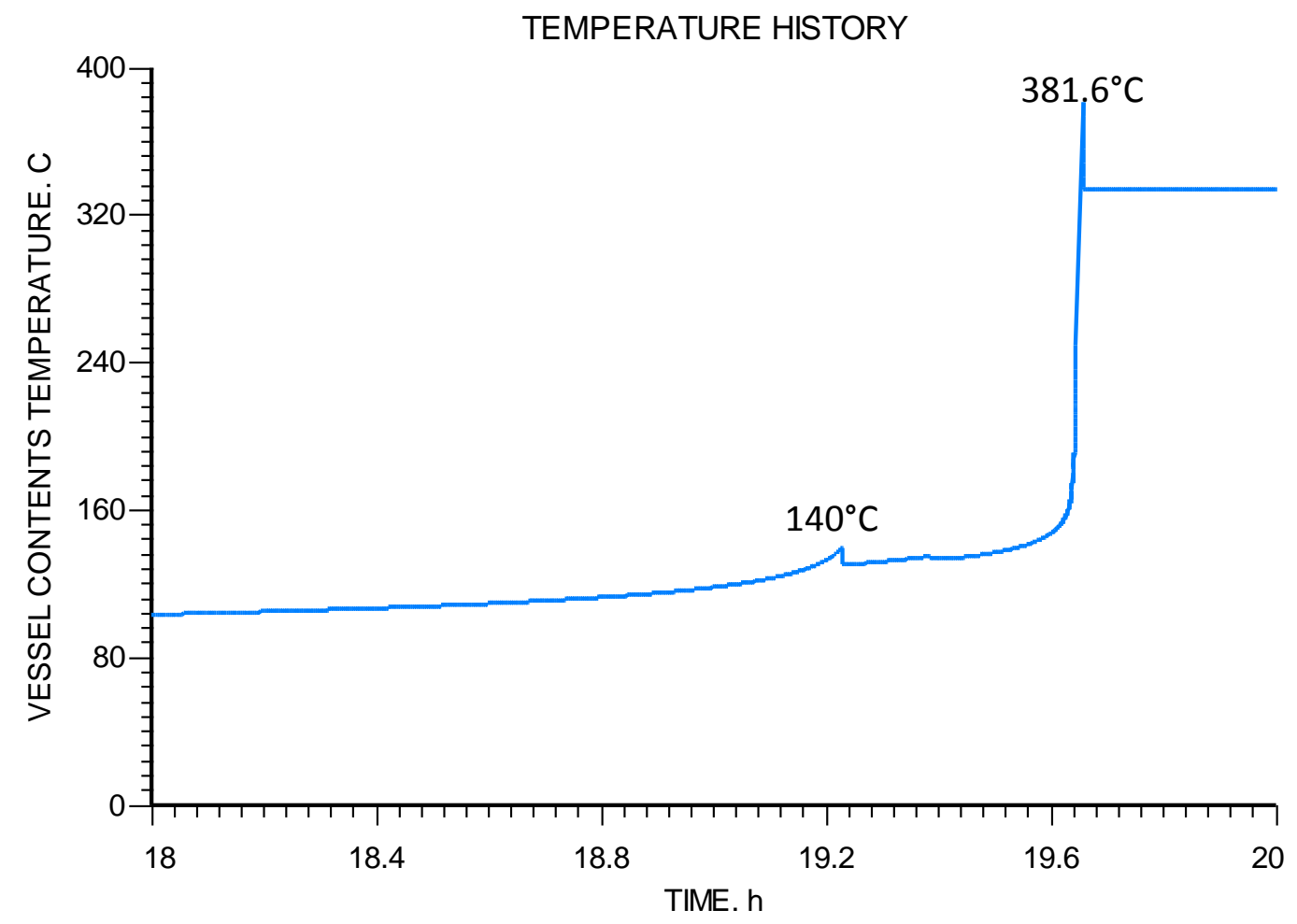

Figure 8: Vessel component mass vs. time profile of vapor relief

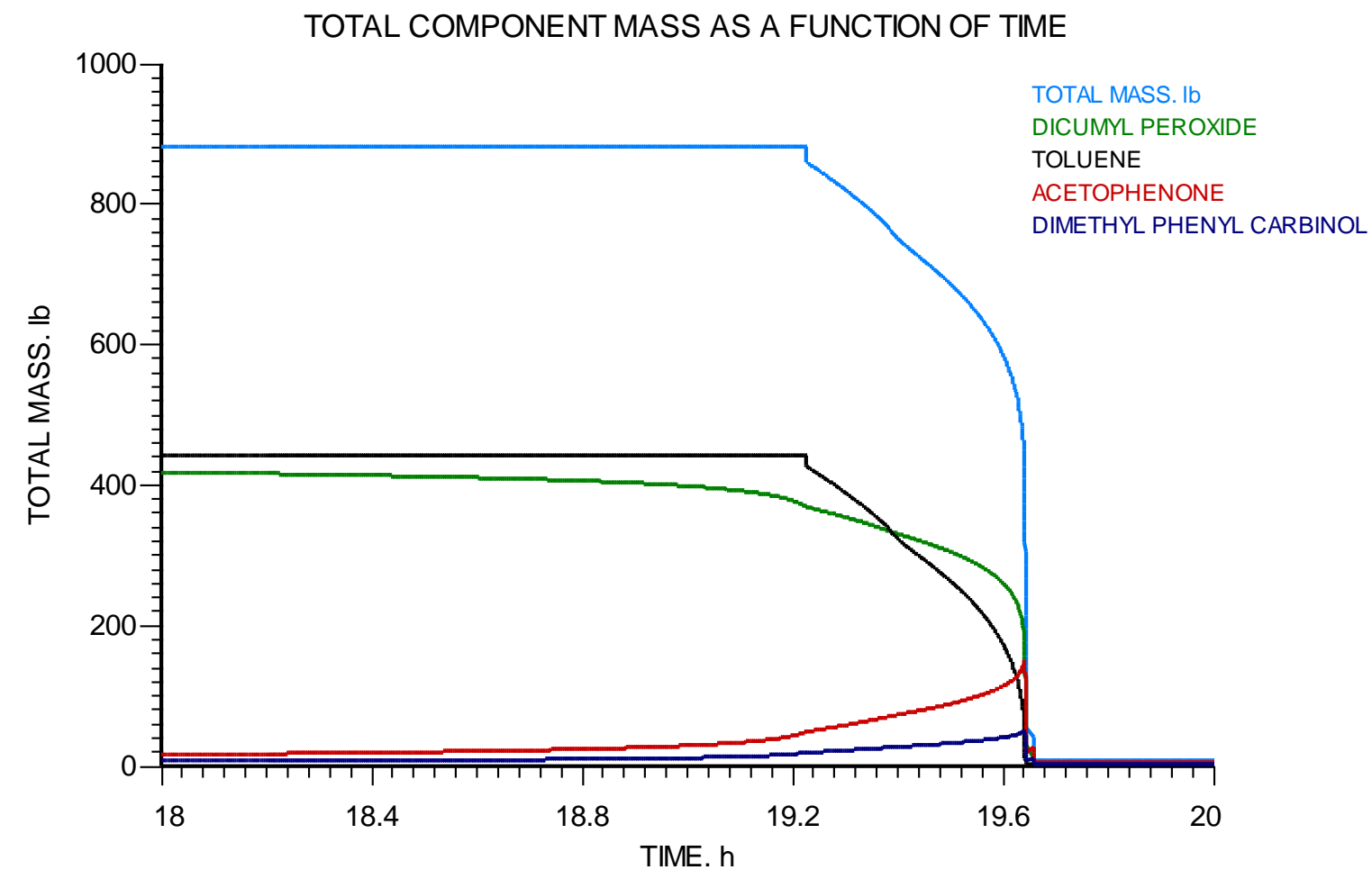




\subsubsection{Two Phase Flow Regime}

The two-phase flow regime includes homogenous, bubbly, and churn turbulent disengagement regimes. DIERS have developed a general recommendation on selecting the disengagement regime based on the viscosity and foamy behavior of the fluid. Since we do not know the foamy behavior of 50\% dicumyl peroxide in toluene solution, we estimated the required rupture disc size based on the most commonly used homogenous disengagement regime.

\subsection{Homogenous Flow Regime}

The vessel under thermal runaway condition resulted in an increase in pressure until the rupture disc burst open at $58 \mathrm{psig}\left(140^{\circ} \mathrm{C}\right)$. Once the rupture disc burst open, the pressure in the vessel dropped to 27.6 psig but there was no sign of temperature drop (Figures 9 and 10). The component mass vs. time plot shows that the majority of the vessel contents are vented soon after the rupture disc bursts open (Figure 11). After a short period of time, the pressure in the vessel rises sharply until all of the remaining vessel contents are vented. The maximum temperature reached was found to be $226.6^{\circ} \mathrm{C}$. The rupture disc size required to keep the vessel pressure below the MAAP (63.8 psig) was found to be $1.50 \mathrm{in}^{2}$.

Figure 9: Vessel pressure vs. time profile of homogenous two-phase relief

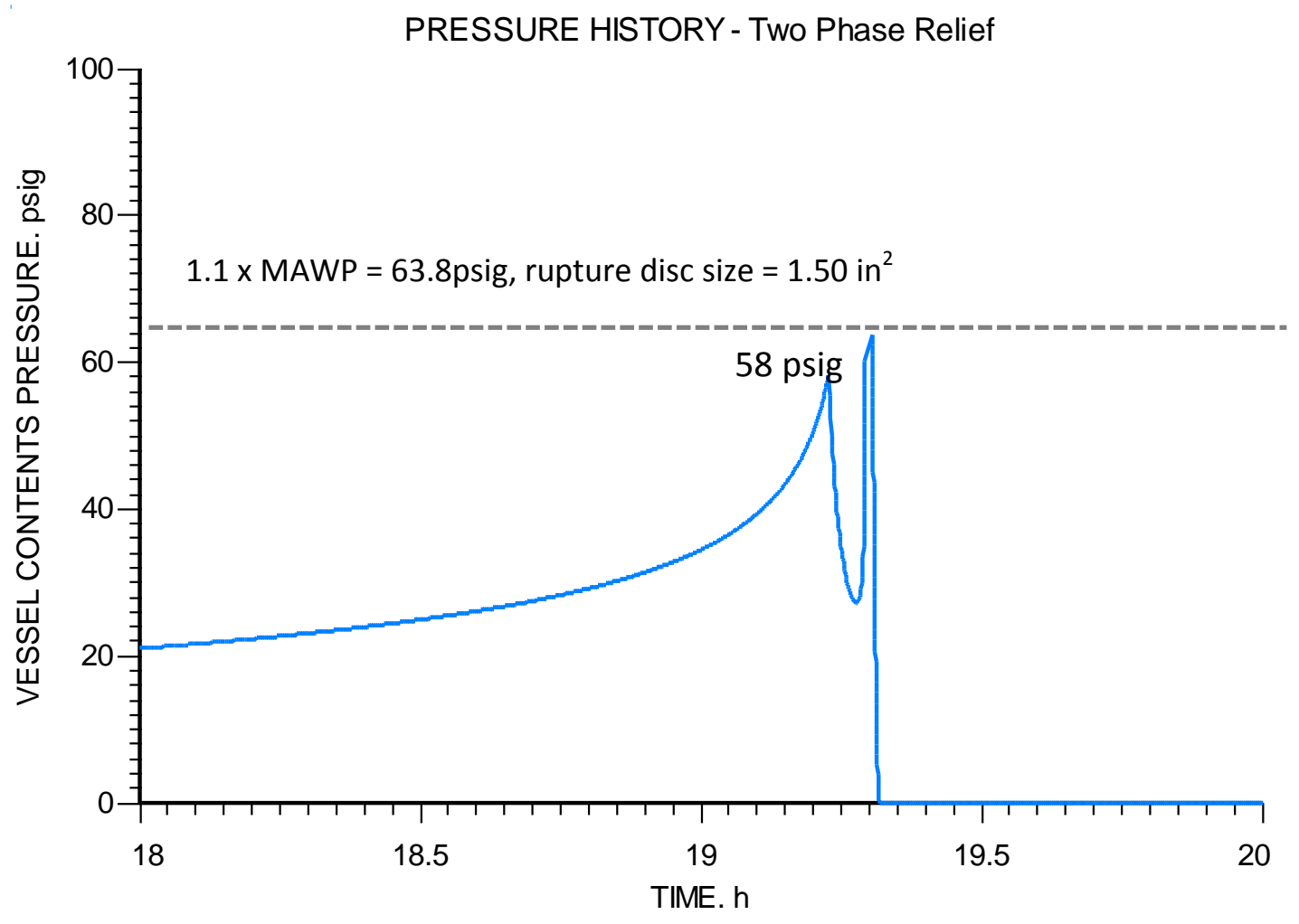


Figure 10: Vessel temperature vs. time profile of homogenous two-phase relief

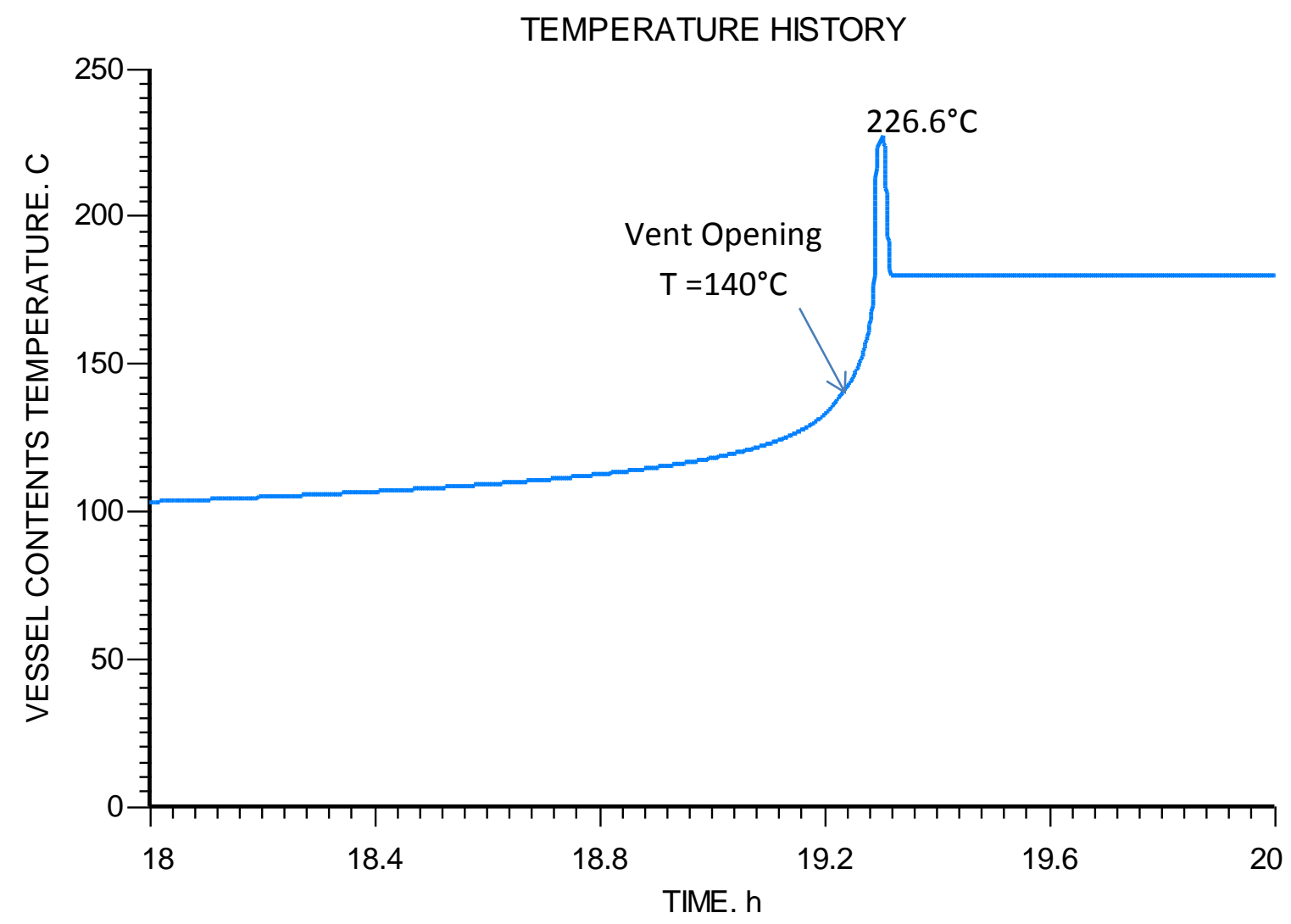


Figure 11: Vessel component mass vs. time profile of homogenous two-phase relief

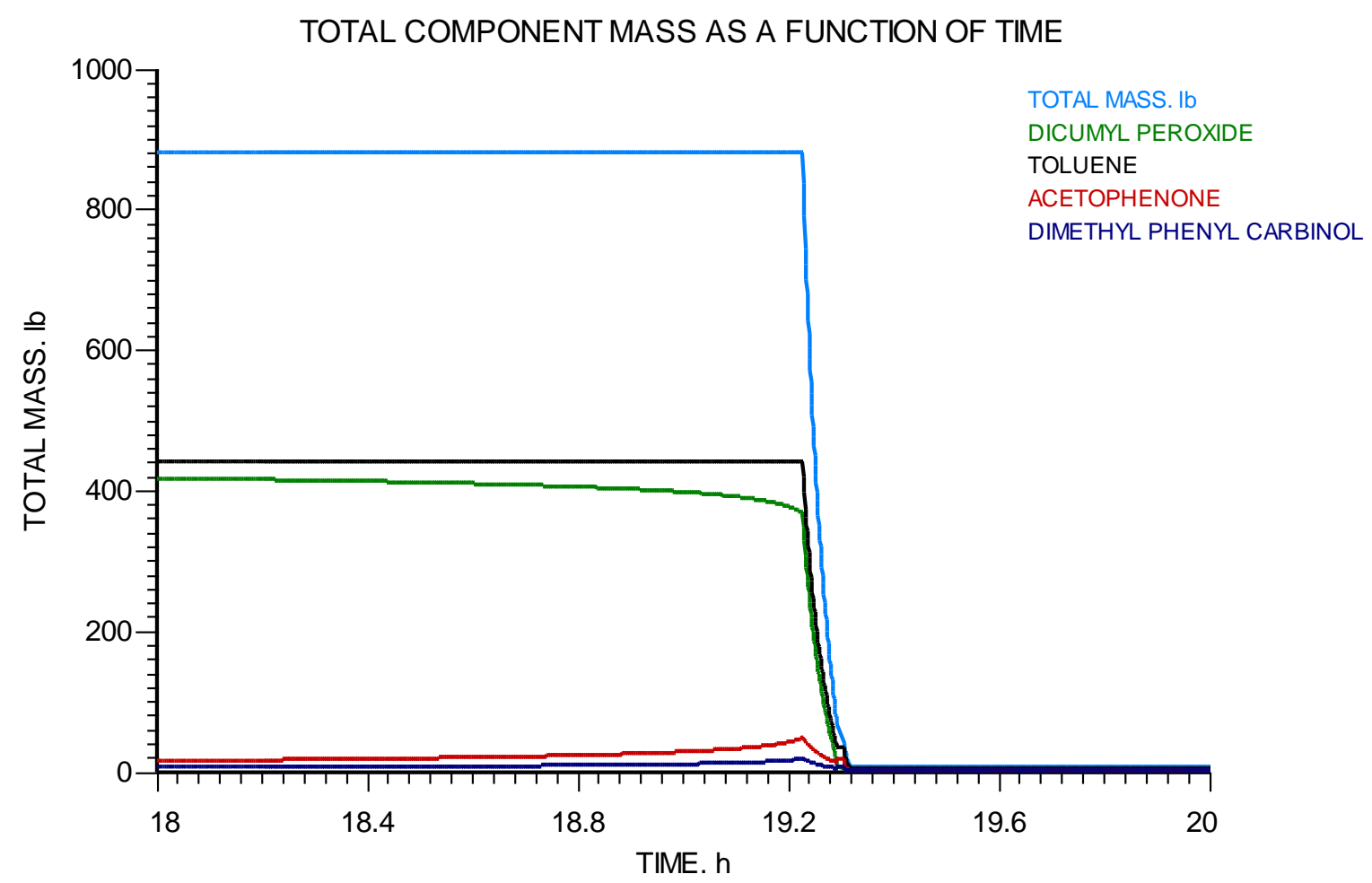

\subsection{Bubbly Flow Regime}

Due to the large disparity between the required rupture disc sizes estimated using the vapor and two-phase homogenous flow regimes, the bubbly disengagement regime was also considered. The vessel under thermal runaway condition resulted in an increase in pressure until the rupture disc burst open at $58 \mathrm{psig}\left(140^{\circ} \mathrm{C}\right)$. Once the rupture disc burst open, the pressure in the vessel dropped immediately to ambient pressure and the temperature dropped to $131^{\circ} \mathrm{C}$ (Figures 12 and 13). The component mass vs. time plot shows that the majority of the vessel contents are vented soon after the rupture disc burst open (Figure 14). For the next $0.35 \mathrm{hr}$, the temperature in the vessel kept rising slowly while the pressure remained relatively constant. When almost all of the toluene in the vessel has evaporated and approximately $11 \mathrm{lbs}$ of dicumyl peroxide remains, the pressure and temperature in the vessel rises sharply until all of the remaining vessel contents are vented. The rupture disc size required to keep the vessel pressure below the MAAP (63.8 psig) was found to be $3.44 \mathrm{in}^{2}$. 
Figure 12: Vessel pressure vs. time profile of bubbly two-phase relief

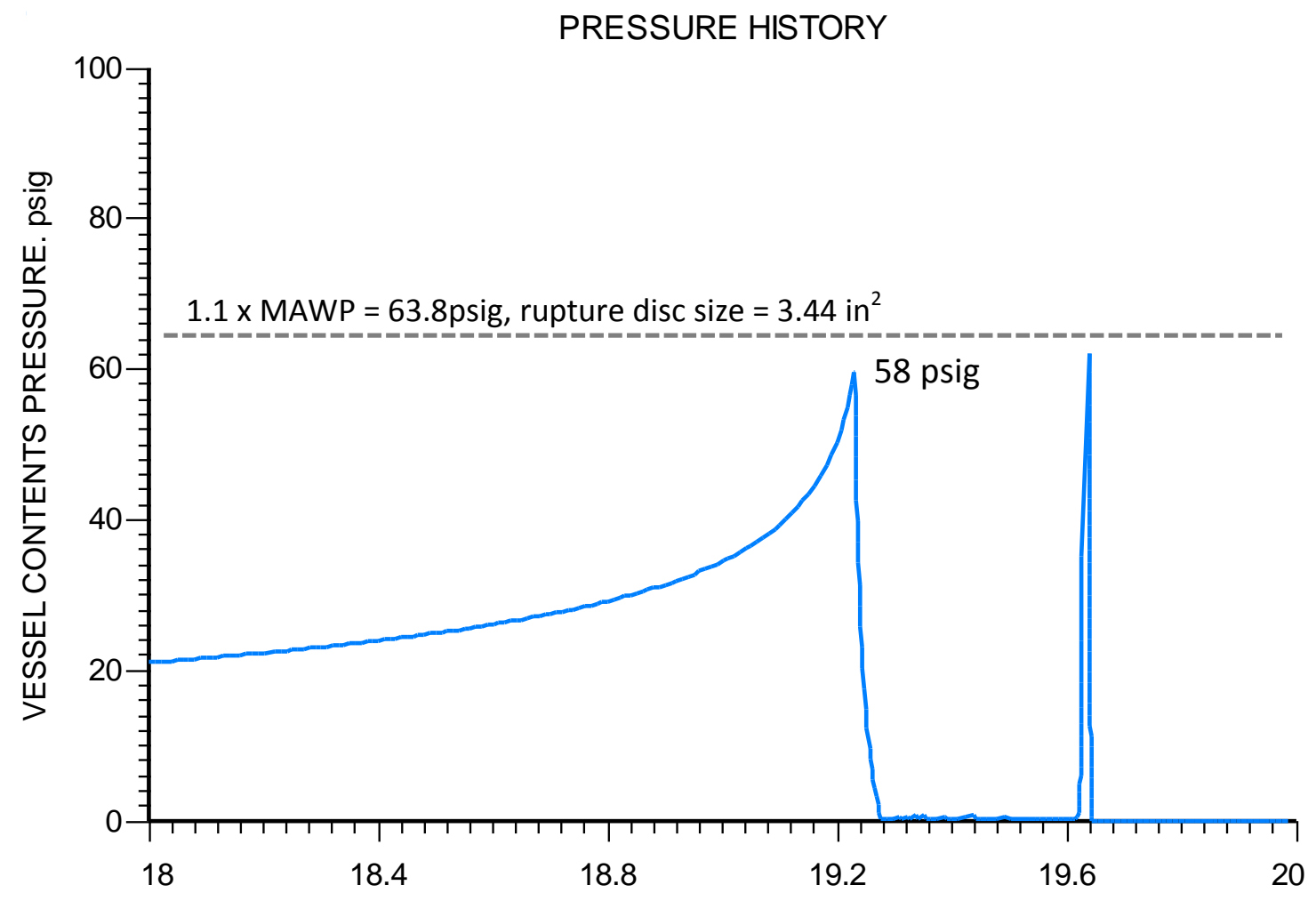

Figure 13: Vessel temperature vs. time profile of bubbly two-phase relief

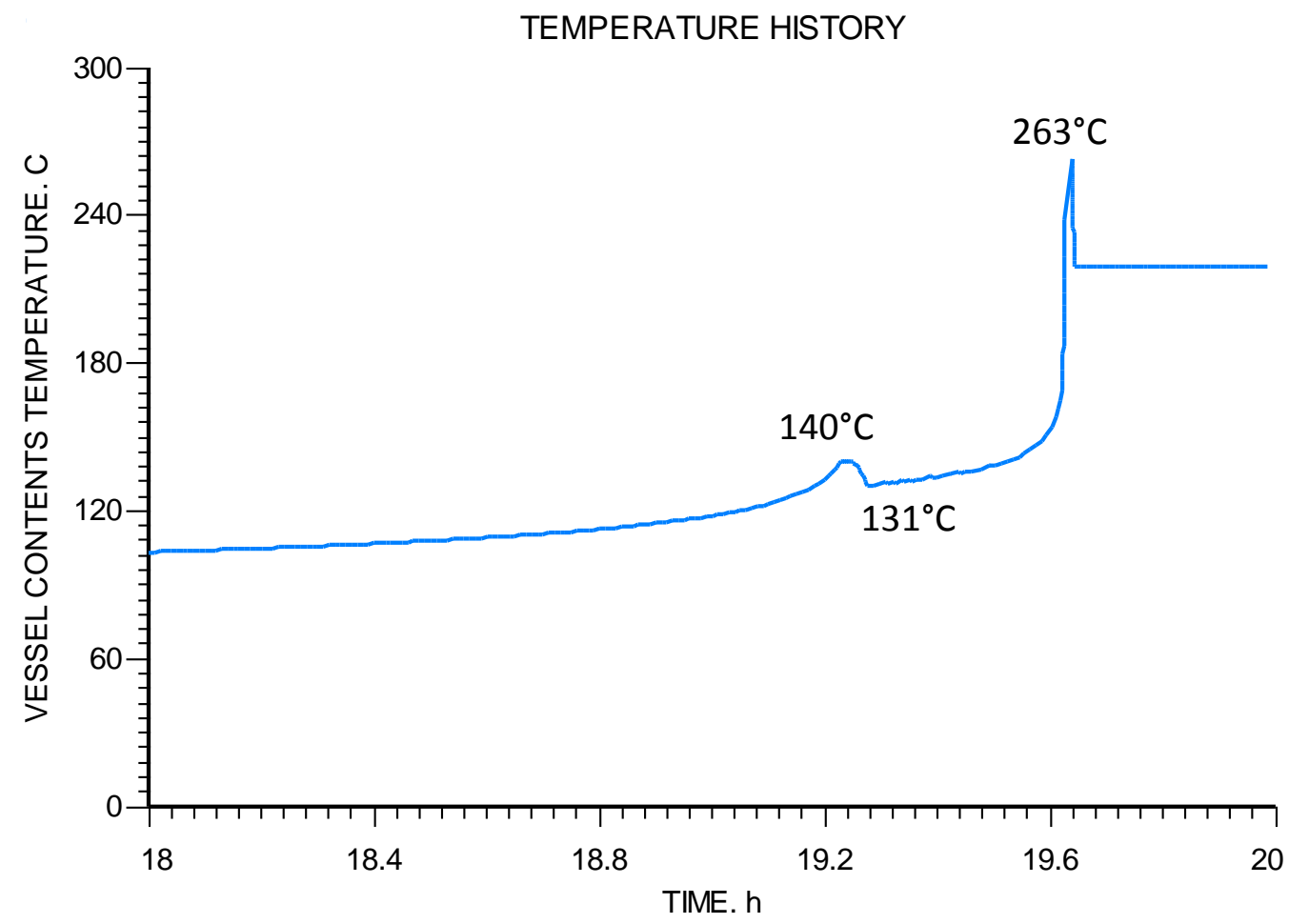


Figure 14: Vessel component mass vs. time profile of bubbly two-phase relief

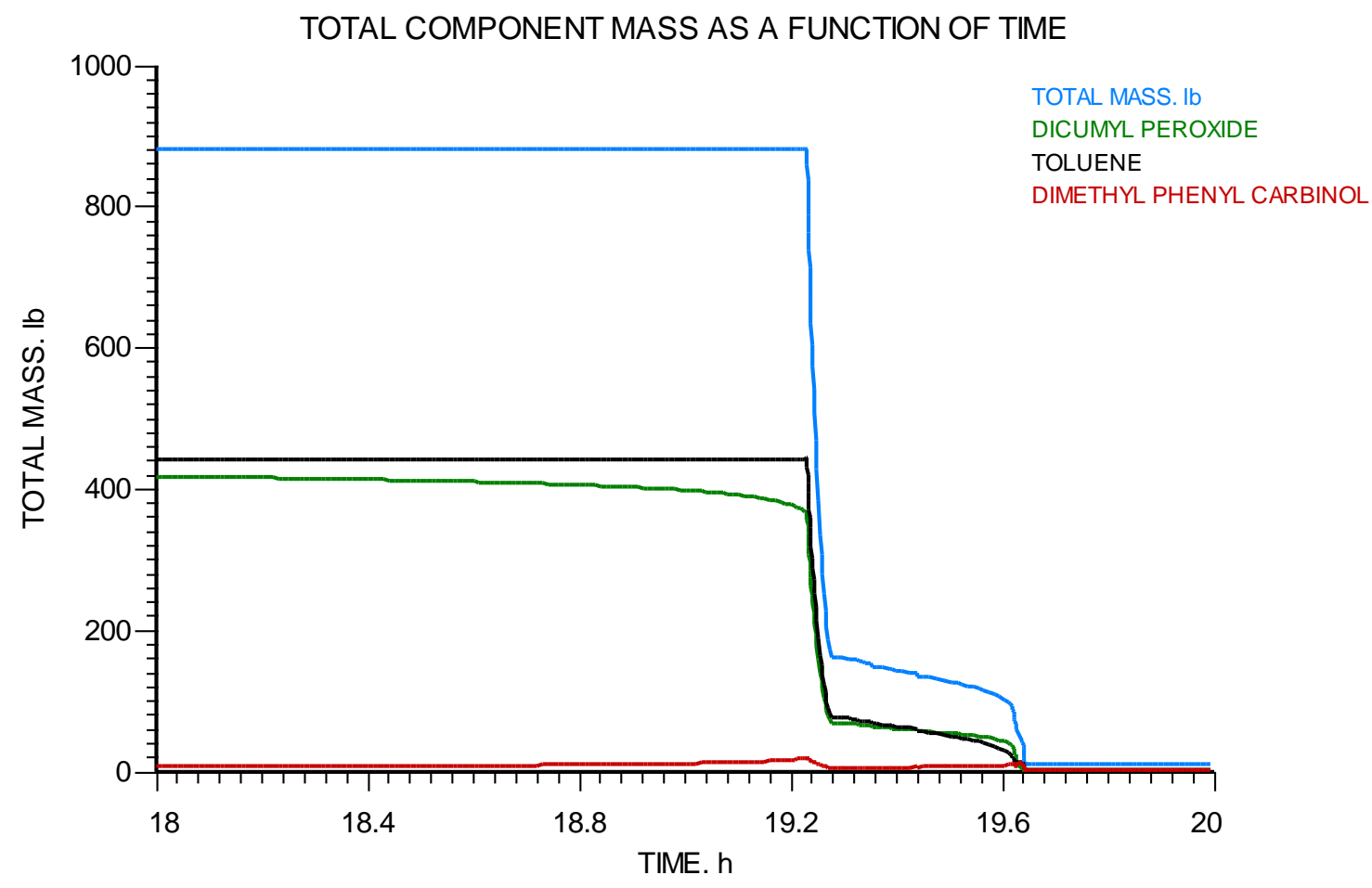

Table 3: Summary of rupture disc size using dynamic computer simulation method

\begin{tabular}{|l|c|}
\hline Description & Relief Size Area $\left(\mathrm{in}^{2}\right)$ \\
\hline Vapor Regime & 405 \\
\hline Two Phase Regime & 1.5 \\
\hline Homogenous two phase & 3.44 \\
\hline Bubbly two phase & \\
\hline
\end{tabular}

\subsubsection{Rupture Disc Size Estimation using DIERS Analytical and Direct Scale-up Methods}

Singh et $\mathrm{al}^{5}$ reported the estimated relief vent sizes for 50\% dicumyl peroxide in toluene system using DIERS analytical and direct scale-up methods. Estimations were made using the data collected by Murphy in a low thermal inertia adiabatic calorimeter (APTAC). Relief sizes were estimated for vapor flow regime and two phase flow regime (hybrid flow). The APTAC closed test results were used for estimation of relief size for vapor phase flow regime. APTAC vented test results at vent set pressure of $58 \mathrm{psig}$, were used for the estimation of relief size for two phase flow regime. Test results of closed and vented test results were used to estimate the relief size using area to charge scaling (direct scale-up) method. All the tests were conducted as recommended in DIERS methodology. The estimated relief areas are summarized in Table 4. 
The visual observations were made during the vented APTAC test. As soon as vent was opened, liquid with vapor came out, followed by vapor only. A sudden "puff" sound was noticed at the end. This indicates that flow regime of this system is the combination, and in sequence of two phase flow, followed by vapor flow (toluene) and then two phase flow (decomposition products of dicumyl peroxide). Dynamic computer simulation for vapor phase considers that all the vapor (toluene) left the vessel and left a significant amount of unreacted dicumyl peroxide inside. Once toluene inventory in the vessel reduces (less heat sink), the temperature of the vessel increases, resulting in increased decomposition rate of dicumyl peroxide. A sharp increase in decomposition of dicumyl peroxide results in a sharp increase in temperature and pressure in the vessel resulting in higher relief size area. The DIERS analytical method estimate for vapor phase is based on the maximum pressure rise rate and the difference in the pressure between vent pressure and the end pressure in the closed vessel. Since decomposition of dicumyl peroxide happens while all the solvent (heat sink) is inside vessel, a significantly lower pressure rise rate as well as end pressure and temperature are attained, which resulted in a lower relief size.

Table 4: Summary of rupture disc size estimation using DIERS methodology

\begin{tabular}{|l|c|}
\hline Description & Relief Size Area $\left(\mathrm{in}^{2}\right)$ \\
\hline Vapor Regime & 3.81 \\
\hline Two Phase Regime (Hybrid/Gassy) & 29.5 \\
\hline Vented to open vessel & \\
\hline Area:Charge Scaling (direct scale-up) & 4.1 \\
\hline Vented to open vessel & \\
\hline
\end{tabular}




\section{Conclusion}

Rupture disc sizes were estimated using computational method and the results were compared (Table 5) with the estimates reported by Singh et $\mathrm{al}^{5}$, using DIERS direct scale-up methods. The results for DIERS direct scale-up methods include both vapor and two phase homogenous flow regimes $^{1}$.

Table 5: Comparison of rupture disc sizes for dynamic computer simulation vs. DIERS methodology

\begin{tabular}{|l|c|c|}
\hline Description & \multicolumn{2}{|c|}{ Relief Size Area in $^{2}$ ) } \\
\hline & $\begin{array}{c}\text { Computer } \\
\text { Simulation }\end{array}$ & $\begin{array}{c}\text { DIERS Analytical and Direct } \\
\text { Scale-up Methods }\end{array}$ \\
\hline Vapor Regime & 405 & 3.81 \\
\hline Two Phase Regime (Hybrid/Gassy) & 1.5 & 29.5 \\
\hline Homogenous & 3.44 & \\
\hline Bubbly & & \\
\hline Area:Charge Scaling (direct scale-up) & NA & 4.1 \\
\hline Vented to open vessel & \multicolumn{2}{|c|}{} \\
\hline
\end{tabular}

The rupture disc size estimations for vapor phase relief were found to be $405 \mathrm{in}^{2}$ using dynamic computational method in comparison to $3.81 \mathrm{in}^{2}$ using the analytical method.

The rupture disc size estimations for two phase flow regime were found to be 1.5 in $^{2}$ (homogenous) and 3.44 in $^{2}$ (bubbly) using dynamic computational method in comparison to 29.5 in $^{2}$ using DIERS analytical method.

The rupture disc size estimates for two phase flow regimes $\left(1.5 \mathrm{in}^{2}\right.$ and $\left.3.44 \mathrm{in}^{2}\right)$ were found to be much closer to the estimates of $4.1 \mathrm{in}^{2}$, using DIERS area to charge scaling (direct scale-up) method.

The dynamic simulation method rendered a higher relief size than the estimate from DIERS analytical method. In general the DIERS analytical method predicts a larger relief size than a dynamic simulation. In this case, the analytical method was unable to predict the later temperature and pressure increase due to continued reaction after boil off of the solvent.

The relief size estimates for two phase flow regime using dynamic computer simulation method resulted in significantly lower size than DIERS analytical method. In general, DIERS analytical method estimates are conservative estimates.

The dicumyl peroxide in toluene is a complex system and knowing a flow regime is critical in order size accurately. It is recommended to evaluate the flow regime using DIERS methodology and use the correct flow regime for the estimation of relief size. Dynamic simulation method is a better alternative method. 


\section{References}

1. The Design Institute for Emergency Relief System (DIERS) Project Manual, American Institute of Chemical Engineers, New York, NY 1992.

2. G.A Melhem, H.G. Fisher and D.A. Shaw, An advanced method for the estimation of reaction kinetics, scale up, and pressure relief design, Process safety progress, vol. 14, no. 1, January (1995),1-21.

3. J.C. Leung and H.K. Fauske, Runaway system characterization and vent sizing based on DIERS Methodology, Plant Operation Progress, Vol. 6, No.2, April 1987, pg 77-83.

4. M.R. Murphy Model based scale-up of dicumyl peroxide decomposition. DIERS User Group meeting May 9, 2012, Concord, MA.

5. S.K Singh and M.R. Murphy. Emergency relief system design for reactive systems using direct scale-up methods. American Institute of Chemicals Engineers, Proceedings of $11^{\text {th }}$ Global Congress on Process Safety, Austin 27-29, 2015.

6. Operation Manual ARC 254, NETZSCH Instruments North America, LLC., Burlington, MA, USA. 